\title{
HRTEM investigation of phase stability in alumina-zirconia multilayer thin films
}

\author{
CHANCHAL GHOSH ${ }^{1, *}$, DIVAKAR RAMACHANDRAN ${ }^{1}$ ， G BALAKRISHNAN ${ }^{2}$, P KUPPUSAMI ${ }^{3}$ \\ and E MOHANDAS ${ }^{1}$ \\ ${ }^{1}$ Materials Synthesis and Structural Characterisation Division, Physical Metallurgy Group, Metallurgy and Materials \\ Group, Indira Gandhi Centre for Atomic Research, Kalpakkam 603 102, Tamil Nadu, India \\ ${ }^{2}$ Department of Physics, PERI Institute of Technology, Chennai 600 048, Tamil Nadu, India \\ ${ }^{3}$ Centre for Nanoscience and Nanotechnology, Sathyabama University, Chennai 600 119, Tamil Nadu, India
}

MS received 3 April 2014; revised 26 June 2014

\begin{abstract}
Phase stability of nanostructured thin films can be significantly different from the stability of the same materials in bulk form because of the increased contribution from surface and interface effects. $\mathrm{Zirconia}\left(\mathrm{ZrO}_{2}\right)$, stabilized in tetragonal and cubic phases, is a technologically important material and is used for most high temperature applications. In literature, zirconia can be found to be stabilized in its high temperature phases down to room temperature via two routes, doping with divalent or trivalent cations and crystallite size controls. Apart from these, in the alumina/zirconia thin-film multilayer system, a constraining effect on the zirconia layers provides another route to stabilization of the tetragonal zirconia phase at room temperature. However, in such nanostructured geometries, at high temperatures, the small diffusion lengths involved can influence the phase stability. The present work deals with the high-resolution transmission electron microscope (HRTEM) studies of pulsed laser ablated aluminazirconia thin-film multilayers in the as deposited state and annealed up to $1473 \mathrm{~K}$ at $2 \times 10^{-5}$ mbar. Conventional techniques such as X-ray diffraction lack the ability to detect localized phase changes at nanometre length scales and also for the low volume fraction of newly formed phases. Cross-sectional HRTEM techniques have been successful in detecting and characterizing these interactions.
\end{abstract}

Keywords. Alumina + zirconia multilayers; laser ablation; high-resolution transmission electron microscopy; phase stabilization; amorphous zones.

\section{Introduction}

Zirconia $\left(\mathrm{ZrO}_{2}\right)$ has attracted extensive attention among material scientists owing to its wide technological applications ranging from thermal barrier coatings ${ }^{1,2}$ to radioactive waste immobilization matrix. ${ }^{3}$ Zirconia possesses interesting properties such as high refractive index, high resistance to oxidation, good tribological properties, high fracture toughness, high bending strength and tensile strength, oxygen ion conductivity, low thermal conductivity and high coefficient of thermal expansion. ${ }^{4}$

Pure $\mathrm{ZrO}_{2}$ exists in three structural modifications: monoclinic $\left(\mathrm{m}-\mathrm{ZrO}_{2}\right)$, tetragonal $\left(\mathrm{t}-\mathrm{ZrO}_{2}\right)$ and cubic $\left(\mathrm{c}-\mathrm{ZrO}_{2}\right)$ of which the tetragonal $\left(\mathrm{t}-\mathrm{ZrO}_{2}\right)$ phase that is stable at $1443-$ $2643 \mathrm{~K}$ is important for most high temperature applications and is required to be stabilized down to room temperature. ${ }^{5}$ Two approaches can be adopted for this purpose: (i) doping and (ii) size control. Doping zirconia with trivalent (e.g., Y and rare earth elements) or divalent (e.g., $\mathrm{Ca}, \mathrm{Mg}$ ) cations can partially or fully stabilize the tetragonal or cubic structure at room temperature. ${ }^{6-8}$ The reasons can be stated as (a) the diffused metal ions replace the $\mathrm{Zr}^{4+}$ ions from its mean

*Author for correspondence (chanchal@igcar.gov.in) equilibrium positions and hence the $c / a$ ratio is also getting modified. The change in the $c / a$ axial ratio with composition for $\mathrm{ZrO}_{2}$ doped with other binary and ternary metal oxides demonstrates the phase stability of $\mathrm{ZrO}_{2} \cdot{ }^{9}$ And (b) also the lattice oxygen ion vacancies in $\mathrm{ZrO}_{2}$ generate at high temperature are primarily responsible for the stabilization of the tetragonal or cubic phases at high temperatures. To accommodate the thermally generated oxygen ion vacancies, the structure of $\mathrm{ZrO}_{2}$ changes to the one having eight-fold coordination (tetragonal or cubic). Now under reduced oxygen partial pressure the same effect can also be obtained by doping divalent or trivalent cations within the $\mathrm{ZrO}_{2}$ lattice. The oxygen ion vacancies can be generated at room temperature via this mechanism as a result of charge balance which in turn stabilized the high temperature tetragonal and cubic phases down to room temperature. ${ }^{10,11}$

On the other hand, stabilization of tetragonal morphology at room temperature can also be achieved by reducing crystallite size of zirconia below a critical size range. ${ }^{12-15}$ The phase stability of zirconia changes drastically with the decrease in the grain size, especially in the nano-sized regime. ${ }^{16}$ It was reported from the first-principle calculations that the surface energy of the tetragonal phase is lower than that of monoclinic phase and a reduction in the grain 
size below a critical value can stabilize the high temperature tetragonal phase at lower temperature. First-principle calculations also indicate that amorphous zirconia has the smallest surface energy and thus is thermodynamically the most stable phase and that the surface energy of cubic zirconia is greater than that of monoclinic or tetragonal polymorphs making it most unstable and difficult to synthesize. ${ }^{9,17}$ Mathematically the role of surface energy in determining the stability of different phases in $\mathrm{ZrO}_{2}$ can also be elaborated. The theoretical variation in the specific surface area as a function of nanocrystalline size has been shown by Shukla and Seal ${ }^{10}$ which is determined by using the relationship

$$
S=6 M / \rho R
$$

where $M$ is the molecular weight, $\rho$ the density and $R$ the nanocrystalline size in $\mathrm{nm}$.

Now for the thin film multilayers where the $\mathrm{ZrO}_{2}$ nanocrystalline sizes are within $\mathrm{nm}$ range, the particles do exhibit large surface area to volume ratio and the surface free energy must also be considered along with the volume energy in determining the change in free energy for monoclinic to tetragonal phase transformation.

Garvie $^{12}$ provided a thermodynamic model for the tetragonal phase stabilization in which at the phase transition temperature

$$
G_{\mathrm{t}}^{\mathrm{v}}+\gamma_{\mathrm{t}} A_{\mathrm{t}}=G_{\mathrm{m}}^{\mathrm{v}}+\gamma_{\mathrm{m}} A_{\mathrm{m}},
$$

where $G_{\mathrm{t}}^{\mathrm{v}}$ and $G_{\mathrm{m}}^{\mathrm{v}}$ are the volume free energies for the tetragonal and the monoclinic structures, respectively. $\gamma_{\mathrm{t}}$ and $\gamma_{\mathrm{m}}$ are the surface free energies (cal $\mathrm{cm}^{-2}$ ), $A_{\mathrm{t}}$ and $A_{\mathrm{m}}$ are the specific surface areas $\left(\mathrm{cm}^{2} \mathrm{~mol}^{-1}\right)$ of the tetragonal and the monoclinic phases, respectively.

Rearranging Equation (2)

$$
G_{\mathrm{t}}^{\mathrm{v}}-G_{\mathrm{m}}^{\mathrm{v}}=\gamma_{\mathrm{m}} A_{\mathrm{m}}-\gamma_{\mathrm{t}} A_{\mathrm{t}} .
$$

Substituting Equation (1) into Equation (3)

$$
\begin{aligned}
& \Delta G_{\mathrm{m} \rightarrow \mathrm{t}}^{\mathrm{v}}=\gamma_{\mathrm{m}}\left(6 M / \rho_{\mathrm{m}} R\right)-\gamma_{\mathrm{t}}\left(6 M / \rho_{\mathrm{t}} R\right), \\
& \Delta G_{\mathrm{m} \rightarrow \mathrm{t}}^{\mathrm{v}}=(6 M / R) *\left[\left(\gamma_{\mathrm{m}} / \rho_{\mathrm{m}}\right)-\left(\gamma_{\mathrm{t}} / \rho_{\mathrm{t}}\right)\right] .
\end{aligned}
$$

On the basis of the above equations it can be clearly stated that in the nm size range surface energy has a greater role in determining the phase transformational behaviour in $\mathrm{ZrO}_{2}$. Based on the works of several researchers ${ }^{18-22}$ the critical size of $10 \mathrm{~nm}$ can be obtained on the basis of thermodynamic considerations. The surface energy theory clearly suggests a critical size of $10 \mathrm{~nm}$ below which the high temperature tetragonal structure is thermodynamically stable at room temperature within an isolated, strain free, $\mathrm{ZrO}_{2}$ nanolaminates.

Multilayer thin films of alumina and zirconia can be synthesized using different techniques such as plasma spraying, ${ }^{23}$ slip casting, ${ }^{24}$ reactive sputtering ${ }^{25-28}$ and electron beam evaporation. ${ }^{29}$ However, these techniques are not reliable for the deposition of the nanometre thickness layers. In the present paper a pulsed laser deposition
(PLD) system with excimer laser has been used to deposit nanometre thickness thin films. The main advantages in the processing of multilayers using PLD are the production of stoichiometric films of multi-component systems and low processing temperature. Besides, by controlling the number of pulses, a fine control of film thickness can be achieved. A fast response in exploring new material systems is another unique feature of PLD compared with other deposition methods. $^{30,31}$

Unlike $\mathrm{CeO}_{2}$ and $\mathrm{Y}_{2} \mathrm{O}_{3}$ which form solid solutions with $\mathrm{ZrO}_{2}$ and change the phase boundary, $\mathrm{Al}_{2} \mathrm{O}_{3}$ can alter the stability through constraint imposed by grain size. ${ }^{32,33}$ In this paper we demonstrate the combined effect of alumina addition and its nanoscale layer thickness on the stabilization of tetragonal zirconia down to room temperature. We also discuss the formation of amorphous zones due to intermixing of $\mathrm{Al}_{2} \mathrm{O}_{3}$ and $\mathrm{ZrO}_{2}$ and in situ phase separation at elevated temperature. Conventional techniques are inadequate to detect such changes at the nanometre scale. Highresolution transmission electron microscopy (HRTEM) of cross-sectional samples has been used to detect and characterize these phase transformations and intermixing of the layers. The alumina/zirconia multilayer is of interest for the development of functionally graded thermal barrier coating having high wear and oxidation resistance. The present work examines the integrity and phase stability of such multilayers in the as deposited and at high temperature annealed conditions.

\section{Materials and methods}

$\mathrm{Al}_{2} \mathrm{O}_{3} / \mathrm{ZrO}_{2}$ multilayers were synthesized by pulsed laser deposition using $\mathrm{KrF}$ excimer laser $(\lambda=248 \mathrm{~nm})$ using sintered targets of alumina and zirconia (99.99\% purity) at partial pressure of oxygen of $3 \times 10^{-3}$ mbar at room temperature. PLD was used to obtain the multilayers of alumina and zirconia on a $\mathrm{Si}(100)$ single crystal substrate with different zirconia layer thickness (15 and $7 \mathrm{~nm}$ ) keeping the alumina thickness same $(5 \mathrm{~nm})$. The sintered targets used were pure $\alpha$-alumina phase with a rhombohedral structure ( $a=$ $4.75 \AA, c=12.99 \AA$ ) in agreement with JCPDS data (\# 461212) and a pure zirconia pellet that had a higher volume fraction of monoclinic and small fraction of tetragonal phase (JCPDS \# 65-1025 and \# 50-1089, respectively). The multilayer sample was subsequently in situ heat treated up to $1473 \mathrm{~K}$ under vacuum of $2 \times 10^{-5}$ mbar in a high temperature X-ray diffractometer (INEL XRG-3000 Diffractometer) attached with position-sensitive detector and Buehler 2.4 HDK high temperature camera. ${ }^{34-36}$

Cross-sectional HRTEM (XTEM) of the as-deposited specimen was carried out on multilayers of alternating $\sim 15 \mathrm{~nm}$ zirconia and $\sim 5 \mathrm{~nm}$ alumina thin films. For XTEM of the annealed one, multilayer sample with zirconia thickness $\sim 7 \mathrm{~nm}$ was selected. The experimental details of the asdeposited multilayer with $7 \mathrm{~nm}$ zirconia layers has already been reported somewhere else. ${ }^{36}$ 
To prepare the XTEM specimen, the multilayer samples were diced into $1 \times 2 \times 0.5 \mathrm{~mm}$ cuboids and two such pieces were glued with G1 epoxy with the nano-laminates facing each other. The whole assembly was then fitted into titanium slot grids with slot size $2 \times 1.2 \mathrm{~mm}$. This was thinned down mechanically to $\sim 30 \mu \mathrm{m}$ and subsequently ion-milled to electron transparency in Technoorg Linda IV 4 ion miller. Enough care was taken to remove the surface damage layers induced by the high-energy ion milling by low-energy ion milling in a Technoorg Linda IV 6 Gentle Mill.

HRTEM studies were carried out in a JEOL 2000 EX II (T) transmission electron microscope having a point resolution of $0.19 \mathrm{~nm}$ at an operating voltage of $200 \mathrm{kV}$. The microscope was equipped with a Lheritier Multi-Scan CCD camera to record digital images from which quantitative analysis was performed. Phase identification was made from highresolution digital images by calculating power spectra from $\sim 5 \mathrm{~nm}$ wide crystalline regions and analysing them for inter-planar spacings and angles.

\section{Results and discussion}

Figure 1 shows a relatively low-magnification bright-field image of the alternate layers of zirconia and alumina in crosssection, illustrating the overall nano-laminate structure. The silicon substrate and the G1 epoxy can be observed on two sides of the multilayers. The alumina layer appearing light in the image, clearly separates the polycrystalline zirconia layers, which appear dark due to higher atomic number. It can also be observed that the as-deposited multilayers are well defined, of uniform thickness over large distances and

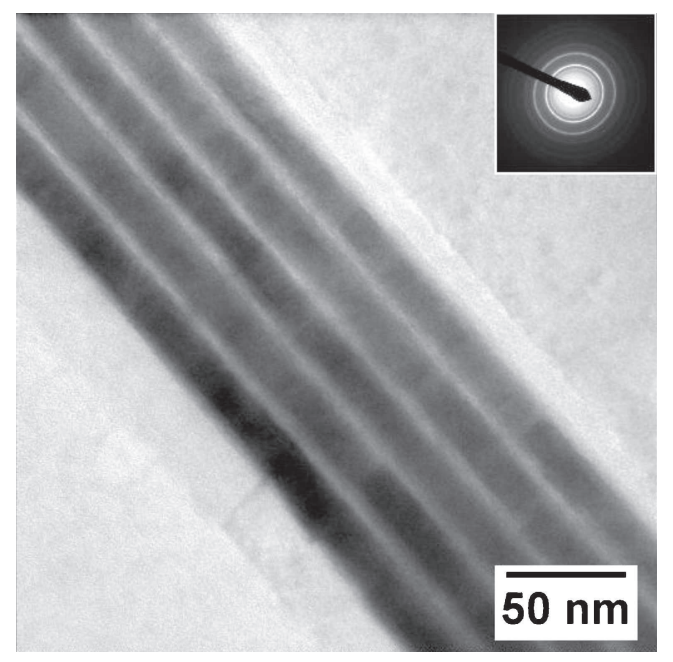

Figure 1. Low-magnification bright-field image showing multilayers of $\mathrm{Al}_{2} \mathrm{O}_{3}$ and $\mathrm{ZrO}_{2}$. Dark bands correspond to $\mathrm{ZrO}_{2}$ while bright bands in between are $\mathrm{Al}_{2} \mathrm{O}_{3}$ layers. Inset shows the $\mathrm{SAD}$ pattern from zirconia-alumina nanolaminate consisting 15-nm-thick zirconia layers. Pattern is indexed as polycrystalline mostly in monoclinic phase. No evidence for crystalline alumina is present. with flat interfaces in between the two phases. The thickness of the alumina and zirconia nano-laminates is observed to be 5 and $15 \mathrm{~nm}$, respectively.

The inset of figure 1 shows selected area electron diffraction (SAD) pattern from the multilayer region studied above, containing both $\mathrm{Al}_{2} \mathrm{O}_{3}$ and $\mathrm{ZrO}_{2}$ nano-layers. The rings are mostly indexed as monoclinic zirconia, while a very few are from tetragonal phase. From the ring pattern, it is clear that $\mathrm{ZrO}_{2}$ is polycrystalline. No rings corresponding to crystalline alumina are observed, indicating that the alumina is amorphous in nature. In the as-deposited alumina/zirconia multilayer containing 7-nm-thick zirconia film, alumina is amorphous and zirconia is found to be tetragonal, which has already been reported by the authors somewhere else. ${ }^{36}$

Figure 2 shows the HRTEM images from both alumina and zirconia region. The alumina layers are observed to be totally amorphous in nature, while individual zirconia nanocrystallites are seen in the zirconia layers. The image shows that the size of the individual zirconia crystallites is invariably equal to, or slightly smaller than the thickness of the zirconia layer. The observed lattice structures have been analysed for spacings and angles, and individual crystallites can be identified as tetragonal or monoclinic phases of zirconia in many cases, when suitably oriented. A couple of examples are annotated on the right side of figure 2 .

The lattice spacings of the zirconia nanocrystallites were determined by measuring spot positions in the power spectrum corresponding to lattice spacing in the HRTEM image. Two such calculated power spectrum has been shown in

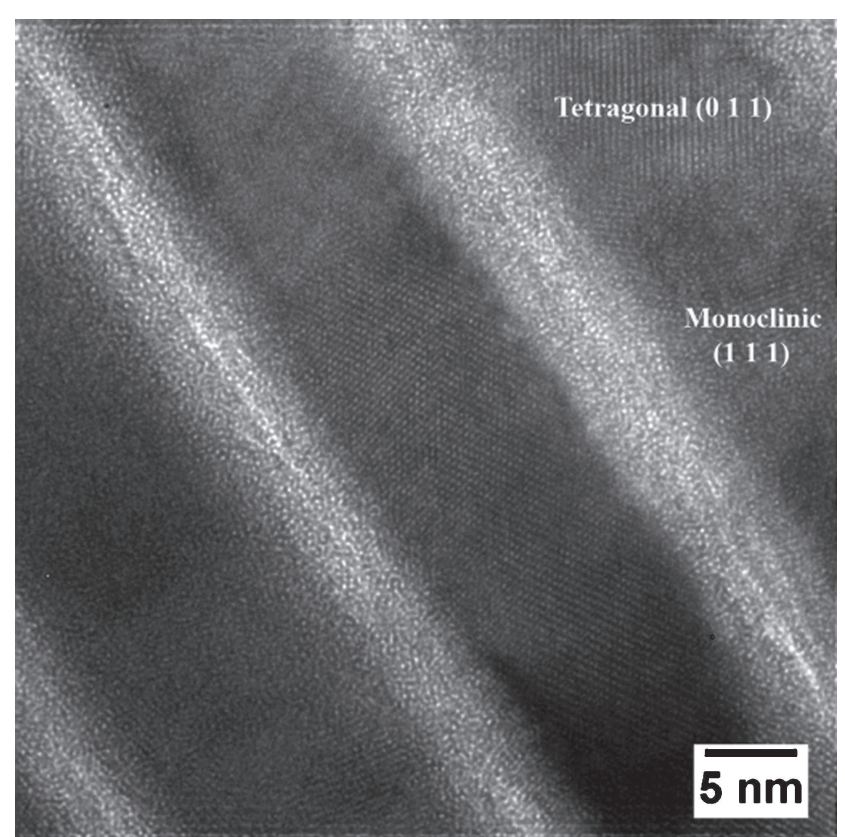

Figure 2. HRTEM of zirconia from a portion of the multilayer showing the crystalline nature with lattice spacing indexed both tetragonal and monoclinic structure. There is no evidence of crystallization from the alumina nanolayer and appear to be totally amorphous. 
figure 3. They have been generated from the top left corner of the micrograph shown in figure 2 and has been indexed with (011) of tetragonal $\mathrm{ZrO}_{2}$ and (111) of monoclinic $\mathrm{ZrO}_{2}$. A large number of power spectrums have been analysed from the different regions of the multilayers and found that $\mathrm{ZrO}_{2}$ is predominantly in the monoclinic structure.

Figure 4 is a relatively low-magnification bright-field micrograph of the multilayers heat-treated at $1473 \mathrm{~K}$, showing the overall structures through its cross-sectional view. Here quite a large number of nano-laminates can be observed along with the silicon substrate on one side. Alumina layers are seen with higher brightness in between

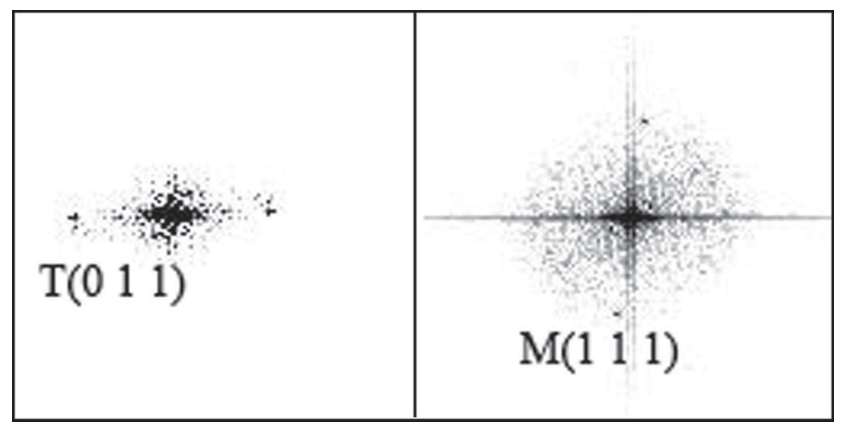

Figure 3. Power spectrum generated from the $\mathrm{ZrO}_{2}$ nanocrystallites shown in figure 2 .

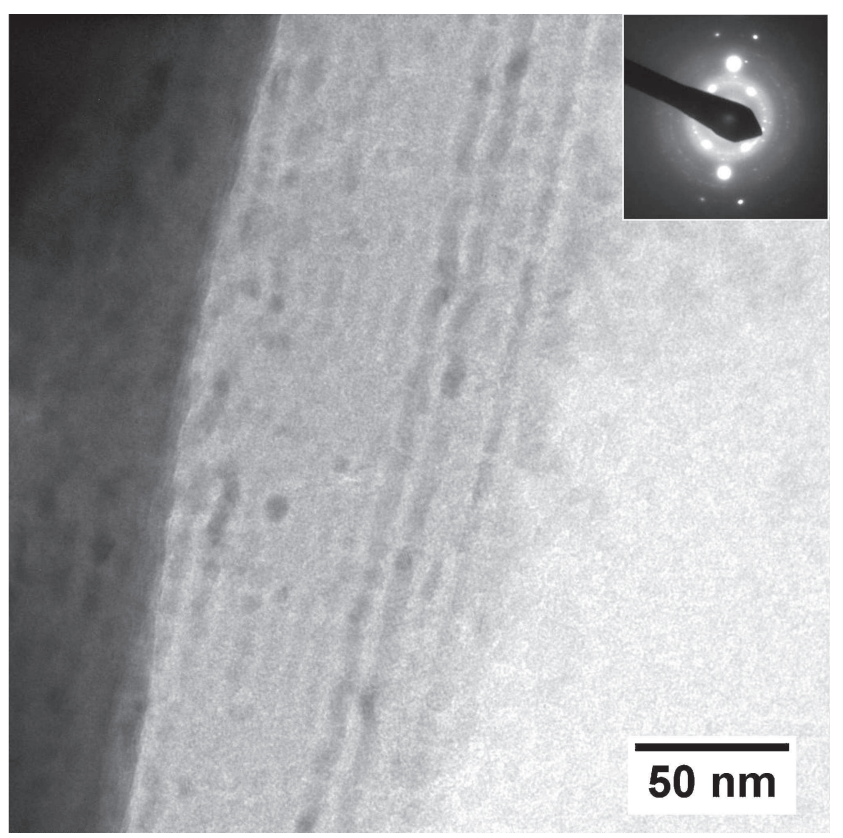

Figure 4. Low-magnification bright-field image showing the cross-sectional view of the $\mathrm{Al}_{2} \mathrm{O}_{3}-\mathrm{ZrO}_{2}$ multilayers. Dark bands correspond to $\mathrm{ZrO}_{2}$ while bright bands in between are $\mathrm{Al}_{2} \mathrm{O}_{3}$ layers. Here the layers are not well resolved at the interfaces and also they are not looking straight throughout. Inset shows SAD pattern from the same region of the multilayers, consisting 7-nm-thick zirconia layers. Pattern is indexed as polycrystalline tetragonal phase. No evidence for crystalline alumina is present. polycrystalline zirconia layers which appear darker in the micrograph. Zirconia nano-laminates are not continuous throughout and are also seen to be distorted in some regions. Nano-layers are not well separated at the interfaces and the interfaces are also not flat. There are discontinuities in the zirconia layers where the nano-laminates cannot be identified separately. The average thickness of each of the nano-layers is measured to be $\sim 7 \mathrm{~nm}$. Figure 4 (inset) is the SAD pattern taken from the same region of the multilayer. It shows a ring pattern, characteristic of diffraction from a polycrystalline specimen, and has been indexed as tetragonal zirconia. The additional bright spots are from the silicon substrate. No rings due to monoclinic zirconia or crystalline alumina have been observed. These results are in agreement with our other structural characterization studies on similar films reported earlier. $^{34-36}$

Figure 5 shows high-resolution phase contrast image from the heat-treated multilayer sample. In contrast to the asdeposited multilayers, the zirconia layers are discontinuous and the interfaces between the zirconia and alumina layers are diffuse. While, most part of the multilayer structures are still evident, groups of crystallites in the zirconia layers are seen to be separated by regions which are seem to be amorphous. This region is actually amorphous and does not appear so due to grain orientation has been confirmed by tilting the specimen in different zone axis orientation. There is a bright/dark contrast difference between the zirconia and alumina layers. Alumina layers are amorphous in all regions. However, in some regions, the distinction between amorphous alumina

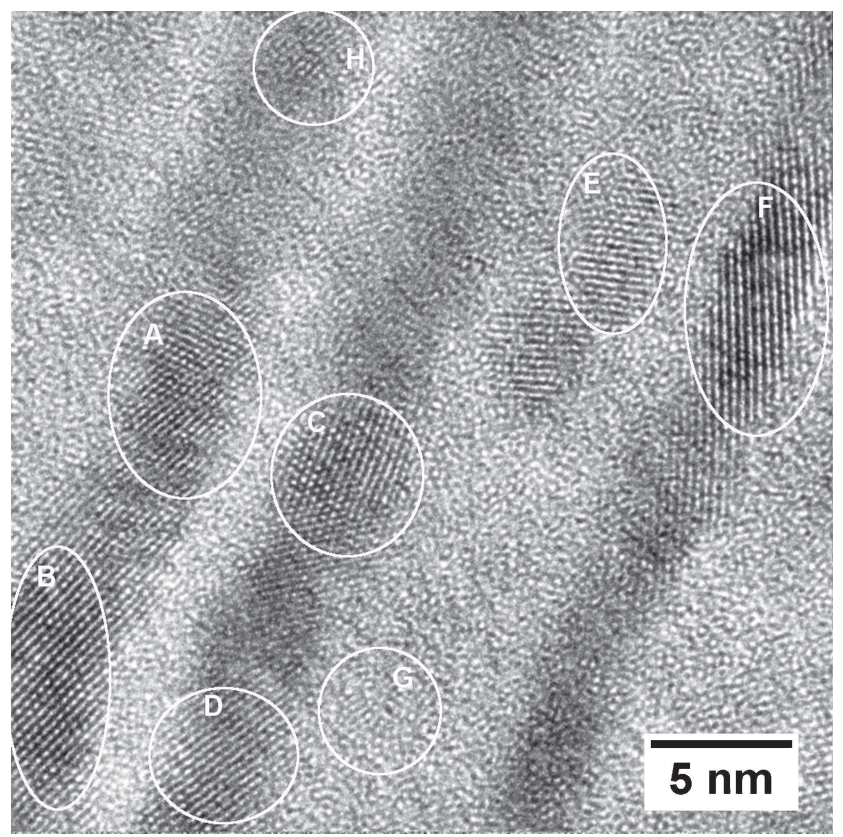

Figure 5. High-resolution lattice image from a multilayer region portion of the heat treated specimen. Lattice planes of $\mathrm{ZrO}_{2}$ alone are imaged since the $\mathrm{Al}_{2} \mathrm{O}_{3}$ layers are amorphous. The layer boundaries are not distinct, $\mathrm{t}-\mathrm{ZrO}_{2}$ phases are observed to be separated by some amorphous regions. 
and zirconia is less clear. The zirconia crystallite sizes $(\sim 7-8 \mathrm{~nm})$ are almost the same as the thickness of the zirconia layer perpendicular to the substrate. Regions corresponding to crystalline zirconia in figure 5 selected for analysis are labelled from A to $\mathrm{H}$. Inter-planar spacings and in suitable cases inter-planar angles, measured on power spectra calculated from each of these regions showed that the crystalline areas in the zirconia layer can be indexed as tetragonal zirconia.

One such measurement is illustrated in figure 6, where a detailed view of the lattice structure of a crystallite in the zirconia layer is presented. The measured lattice spacing is $0.295 \mathrm{~nm}$ with an inter-planar angle of about $\sim 70^{\circ}$. These lattice planes correspond to (011) plane of tetragonal zirconia. Here, the white dots correspond to the atomic columns from the respective crystalline planes. Multislice simulation has been carried out along the [11-1] zone axis of $\mathrm{t}-\mathrm{ZrO}_{2}$ in support of the experimental results shown in the inset of figure 6 . In the simulated image, the interplanar angle is found to be $70.3^{\circ}$, which matches the experimental results.

An important observation of this work is the stabilization of $\mathrm{t}-\mathrm{ZrO}_{2}$ of thickness $7-8 \mathrm{~nm}$ which is well in accordance with critical thickness reported for the free-standing nanocrystalline zirconia in literature. ${ }^{12,14,15,18-22,32}$ In accordance with our earlier XRD-based studies, ${ }^{34-36}$ the present HRTEM evidence shows conclusively that tetragonal $\mathrm{ZrO}_{2}$ has been stabilized in the size range of 7-8 $\mathrm{nm}$ after heat treatment for the multilayer specimen containing 7-nm-thick $\mathrm{ZrO}_{2}$ laminate. A combination of factors can be responsible

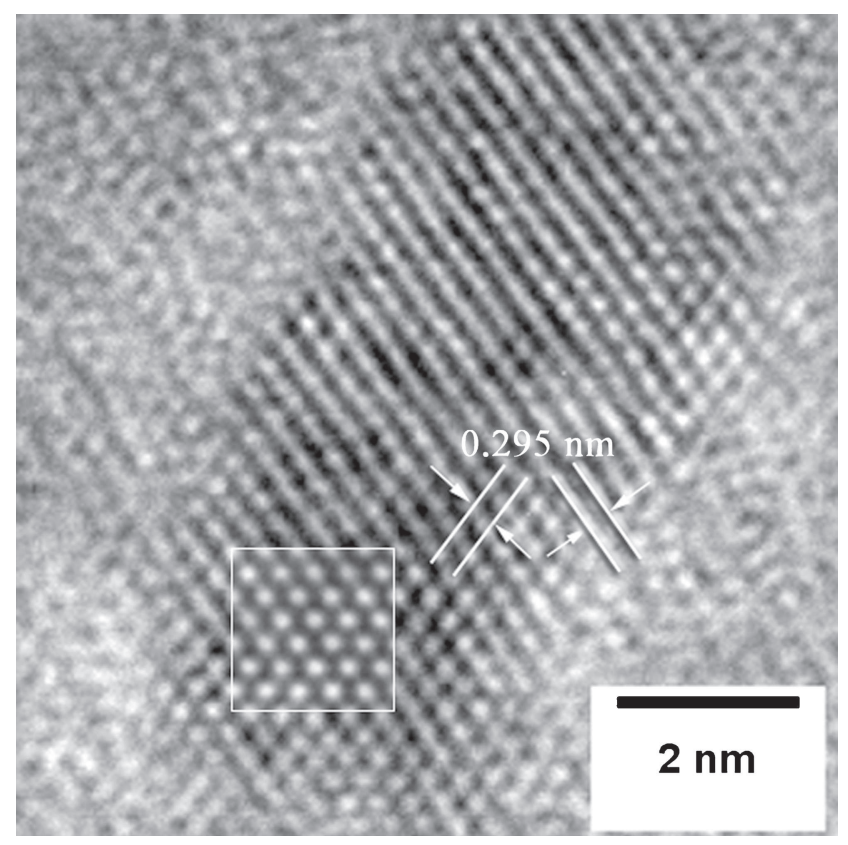

Figure 6. High-resolution lattice image from a zirconia nanocrystallite. The dimension of the crystallite in the perpendicular direction of the substrate is that of the layer width only. The lattice spacings are $0.295 \mathrm{~nm}$ with an interplanar angle of $\sim 70^{\circ}$ corresponding to the (011) plane of $\mathrm{t}-\mathrm{ZrO}_{2}$. (inset) Simulated image of $\mathrm{t}-\mathrm{ZrO}_{2}$ along the $[11-1]$ zone axis imaging the (011) planes. for this. The tetragonal structure of zirconia has a unit cell volume that is less than half that of the monoclinic unit cell. $\mathrm{Al}_{2} \mathrm{O}_{3}$ has high elastic constant $(390 \mathrm{GPa})$, which is almost twice that of $\mathrm{ZrO}_{2}{ }^{37}$ The combination of large volume expansion required for tetragonal $\rightarrow$ monoclinic transformation in the presence of high modulus constraining layers would ensure stability of the tetragonal phase once formed during heat treatment. It is however, the inter-layer and intralayer interface constraints that contribute significantly to phase stability at such small length scales.

The possibility for the formation of amorphous zones in the zirconia layers is another important finding of this study. The presence of such regions may indicate inter-mixing of alumina and zirconia leading to formation of zirconium aluminate phase. These non-crystalline zones are not a phase contrast imaging artefact has been checked by varying the objective lens defocus as well as by tilting the specimen. However, there is indication in literature, that this may indeed take place. It has been reported by Zhao et $a l^{38,39}$ that intermixing of such phases $\left(\mathrm{ZrO}_{2}\right.$ and $\left.\mathrm{Al}_{2} \mathrm{O}_{3}\right)$ could lead to the formation of amorphous $\mathrm{ZrAl}_{x} \mathrm{O}_{y}$. Annealing at high temperatures could result in the initial stages of the nucleation of $\mathrm{t}-\mathrm{ZrO}_{2}$ which is also supported by the phase diagram. ${ }^{40}$ It is interesting to note that, throughout the phase transformation process, the overall multilayer structure is maintained.

These observations are consistent with other experiments, including our own, where alumina layers have been replaced by ceria ${ }^{4-47}$ or yttria. ${ }^{4-54}$ In the ceria/zirconia multilayer system the zirconia nanocrystallites have been observed to be stabilized in the tetragonal phase even at room temperature, whereas the thermally annealed $\mathrm{CeO}_{2} / \mathrm{ZrO}_{2}$ multilayers at $\sim 1473 \mathrm{~K}$ shows the formation of solid solutions near the interfaces. ${ }^{46}$ This is also evident from the equilibrium phase diagram. ${ }^{55}$ The structural similarity and higher solubility of ceria in zirconia could possibly lead to the stabilization of the tetragonal structure in zirconia nanolaminate even at room temperature for $\mathrm{CeO}_{2} / \mathrm{ZrO}_{2}$ multilayers than those of $\mathrm{Al}_{2} \mathrm{O}_{3} / \mathrm{ZrO}_{3}$ multilayers. On the other hand, the addition of $\mathrm{Y}_{2} \mathrm{O}_{3}$ to zirconia significantly promotes the diffusionless cubic phase transition in zirconia, stabilizing the high temperature phases down to room temperature. This transformation is facilitated at a faster rate because of the higher solubility and structural similarities of yttria and zirconia with negligible constraint by yttria.

Another important observation of the present study is the stabilization of the tetragonal phase and not the cubic phase of zirconia because of the annealing at the high temperature. This can be explained based on the coordination geometry associated with the oxygen ion vacancies with $\mathrm{Zr}^{4+}$ ions. Although the oxygen ion vacancies can be generated inside the $\mathrm{ZrO}_{2}$ nanocrystals at the higher temperature but the same effect can also be obtained by replacing $\mathrm{Zr}^{4+}$ ion with trivalent cations. In literature, it has been reported that both oversized (e.g., $\mathrm{Y}^{3+}, \mathrm{Gd}^{3+}$ ) and undersized (e.g., $\mathrm{Al}^{3+}$, $\left.\mathrm{Ga}^{3+}\right)$ trivalent cations are effective for the stabilization of the tetragonal and cubic phases. The doped oversized cations favour the eight-fold coordination and allow associating the oxygen ion vacancies with the host $\mathrm{Zr}^{4+}$ cations. As a result 
small as well as large concentration of oxygen ion vacancies associated with $\mathrm{Zr}^{4+}$ can be produced. Thus both tetragonal and cubic phases can be stabilized at room temperature by doping oversized cations. For doped undersized cations $\left(\mathrm{Al}^{3+}\right.$ size $\left.=0.0535 \mathrm{~nm}\right)$, as in the case of present work, they prefer the six-fold coordination and hence compete with the host $\mathrm{Zr}^{4+}$ cations (size $=0.0720 \mathrm{~nm}$ ) for the oxygen vacancies. As a result only small concentrations of oxygen ion vacancies associated $\mathrm{Zr}^{4+}$ cations can be produced inspite of doping large amount undersized cations. Hence, only tetragonal phase can be stabilized at room temperature by doping undersized $\mathrm{Al}^{3+}$ ions in the zirconia nanocrystals. ${ }^{10,11,56}$

One of the objectives of this paper is also to study the $\mathrm{ZrO}_{2}$ layer thickness on the stabilization of the high temperature tetragonal phase. For that particular purpose multilayers consisted of alternate layers of $\mathrm{ZrO}_{2}$ and $\mathrm{Al}_{2} \mathrm{O}_{3}$ at different zirconia layer thicknesses ( 15 and $7 \mathrm{~nm}$ ) has been synthesized keeping the thickness of the alumina layers same. Further structural characterization suggests that for the 15-nm-thick $\mathrm{ZrO}_{2}$ layers the majority of the phases are of monoclinic structure whereas for the 7-nm-thick $\mathrm{ZrO}_{2}$ layers, the nanocrystallites has been stabilized as tetragonal structure in the as-deposited condition. This is also justified based on the literature reports where the surface energy theory clearly suggests a critical size of $10 \mathrm{~nm}$ below which the high temperature tetragonal structure is thermodynamically stable at room temperature. ${ }^{18-22}$

The phase transformations among monoclinic, tetragonal and amorphous polymorphs ${ }^{57}$ have a significant implication in designing novel $\mathrm{ZrO}_{2}$-based nanostructures for a wide range of technological applications. The present work has also highlighted some of the issues related to the phase and chemical stability of the multilayers in the as-deposited and in the high temperature annealed conditions.

\section{Conclusions}

The HRTEM characterization of the structure and morphology of alumina/zirconia multilayers deposited through PLD have been carried out to study the phase stability of multilayers as a function of temperature. The study has highlighted the phase stability of alumina/zirconia multilayer in the asdeposited and annealed conditions. The results show that the heat-treated zirconia layers contain tetragonal nanocrystallites which remain stable at room temperature. However, the alumina layer remained in amorphous state up to the high temperature annealing of $1473 \mathrm{~K}$. The stabilization of high temperature tetragonal phase at room temperature is supposed to be due to the addition of alumina in the multilayers.

One of the consequences of the interdiffusion of alumina and zirconia in the $\mathrm{nm}$ scale is the possible formation of amorphous intermixed zones which affects the crystalline uniformity of the corresponding nanolayer. The possible formation of the amorphous phases may also lead to the variation of the stoichiometry in the film.

\section{Acknowledgements}

We acknowledge the support and encouragement from Dr M Vijayalakshmi, Associate Director, Physical Metallurgy Group, Dr T Jayakumar, Director, Metallurgy and Materials Group and Dr P R Vasudeva Rao, Director, IGCAR.

\section{References}

1. Wright P K and Evans A G 1999 Solid State Mater. Sci. 4255

2. Zhou X, Balachov I and Macdonald D D 1998 Corros. Sci. 40 1349

3. Gong W L, Lutze W and Ewing R C 2000 J. Nucl. Mater. 277 239

4. Duparre A, Welsch E, Walther H, Kaiser N, Muller H, Hacker E, Lauth H, Meyer J and Weissbrodt P 1990 Thin Solid Films 187275

5. Andritschky M, Cunha I and Alpium P 1997 Surf. Coat. Technol. 94-95 144

6. Grain C F 1967 J. Am. Ceram. Soc. 50288

7. Scott H G 1975 J. Mater. Sci. 101527

8. Stubican V S and Ray S P 1977 J. Am. Ceram. Soc. 60534

9. Christensen A and Carter E 1998 Phys. Rev. B 588050

10. Shukla S and Seal S 2005 Int. Mater. Rev. 501

11. Li P, Chen I-W and Penner-Hahn J E 1994 J. Am. Ceram. Soc. 77118

12. Garvie R C 1965 J. Phys. Chem. 691238

13. Lange F F, Green D J, Heuer A H and Hobbs L W (eds) 1981 Advances in ceramics, vol. 3, science and technology of zirconia (Columbus, OH: American Ceramic Society) p 217

14. Evans A G, Burlingame N, Drory M and Kriven W M 1981 Acta Metall. 29447

15. Aita C R, Wiggins M D, Whig R, Scanlan $C$ M and Gajdardziska-Josifovska M 1996 J. Appl. Phys. 791176

16. Garvie R C 1978 J. Phys. Chem. 82218

17. Kresse G and Furthmuller J 1996 Phys. Rev. B 5411169

18. Chatry M, Henry M and Livage J 1994 Mater. Res. Bull. 29 517

19. Urlacher C, Dumas J, Serughetti J, Mugneir J and Munoz M 1997 J. Sol-Gel Sci. Technol. 8999

20. Xin B, Duan L and Xie Y 2000 J. Am. Ceram. Soc. 831077

21. Noh H-J, Seo D-S, Kim H and Li J-K 2003 Mater. Lett. 572425

22. Nitsche R, Rodewald M, Skandan G, Fuess H and Hahn H 1997 Nanostruct. Mater. 6679

23. Shanmugavelayathamn G, Shoji Y and Kobayashi A 2006 Vaccum 801336

24. Bermejo R, Torres Y, Baudin C, Sanchez-Herencia A J, Pascual J, Anglada M and Llanes L 2007 J. Eur. Ceram. Soc. 271443

25. Schofield M A, Aita C R, Rice P M and GajdardziskaJosifovska M 1998 Thin Solid Films 326106

26. Schofield M A, Aita C R, Rice P M and GajdardziskaJosifovska M 1998 Thin Solid Films 326117

27. Teixeira V, Monteiro J, Duarte J and Portinha A 2002 Vaccum 67477 
28. Gao P, Meng L J, Dos Santos M P, Teixeira V and Andritschky M 2002 Vaccum 64477

29. Leushake U, Krell T, Schulz U, Peters M, Kaysser W A and Rabin B H 1997 Surf. Coat. Technol. 94-95 131

30. Caricato A P, Di Cristoforo A, Fernandaz M, Leggieri G, Luches A, Majni G, Martino M and Mengucci P 2003 Appl. Surf. Sci. 208-209 632

31. Hirschauer B, Chiaia G, GÖthelid M and Karlsson U O 1999 Thin Solid Films 3483

32. Lange F F 1982 J. Mater. Sci. 17225

33. Limarga Andi M, Widjaja Sujano and Yip Tick Hon 2005 Surf. Coat. Technol. 19793

34. Balakrishnan G, Kuppusami P, Sairam T N, Thirumurugesan R, Mohandas E and Sastikumar D 2009 J. Nanosci. Nanotechnol. 91

35. Balakrishnan G, Murugesan S, Ghosh C, Kuppusami P, Divakar R, Mohandas E and Sastikumar D 2009 Proceedings of SPIE, vol. 7404, 74040P, Nanostructured thin films II, San Diego, CA, USA, 5 August 2009

36. Balakrishnan G, Kuppusami P, Murugesan S, Ghosh C, Divakar R, Mohandas E and Sastikumar D 2012 Mater. Chem. Phys. 133299

37. Scanlan C M, Gaijdardziska-Josifovska M and Aita C R 1994 Appl. Phys. Lett. 643548

38. Zhao C, Richard O, Bender H, Caymax M, De Gendt S, Heyns M, Young E, Roebben G, Van Der Biest O and Haukka S 2002 Appl. Phys. Lett. 802374

39. Zhao C, Richard O, Young E, Bender H, Roebben G, Haukka S, De Gendt S, Houssa M, Carter R, Tsai W, Van Der Biest O and Heyns M 2002 J. Non-Cryst. Solids 303144

40. Lakiza S N and Lopato L M 1997 J. Am. Ceram. Soc. 80 893

41. Wang C M, Azad S, Shutthanandan V, McCready D E, Peden C H F, Saraf L and Thevuthasan S 2005 Acta Mater. 531921
42. Yashima M, Sasaki S, Yamaguchi Y, Kakihana M, Yoshimura M and Mori T 1998 Appl. Phys. Lett. 72182

43. Yashima M, Arashi H, Kakihana M and Yoshimura M 1994 J. Am. Ceram. Soc. 771067

44. Sasaki T, Ukyo Y, Kuroda K, Arai S and Saka H 2005 Mater. Sci. Forum 475-479 1351

45. Yashima M 2009 J. Phys. Chem. C. 11312658

46. Ghosh Chanchal, Divakar R, Balakrishnan G, Kuppusami P, Mohandas E and Sastikumar D 2010 IIM NMD-ATM 2010, Bangalore, India, November 14-16, 2010

47. Balakrishnan G, Kuppusami P, Murugesan S, Ghosh Chanchal, Divakar R, Mohandas E and Sastikumar D 2011 Trans. Ind. Inst. Met. 64297

48. Appel C C, Botton G A, Horsewell A and Stobbs W M 1999 J. Am. Ceram. Soc $\mathbf{8 2} 429$

49. Chaim R, Ruhle M and Heuer A H 1985 J. Am. Ceram. Soc. 68427

50. Lanteri V, Chaim R and Heuer A H 1986 J. Am. Ceram. Soc. $69 \mathrm{C}-258$

51. Zhou Y, Lei T C and Sakuma T 1991 J. Am. Ceram. Soc. 74 633

52. Mengucci P, Barucca G, Caricato A P, Di Cristoforo A, Leggieri G, Luches A and Majnia G 2005 Thin Solid Films 478125

53. Piascik J R, Zhang Q, Bower C A, Thompson J Y and Stoner B R 2007 J. Mater. Res. 221105

54. Mishra Maneesha, Kuppusami P, Reddy V R, Singh Akash, Chinnamma G, Ghosh Chanchal, Divakar R and Mohandas E 2013 J. Nanosci. Lett. 34

55. Duwez P and Odell F 1950 J. Am. Ceram. Soc. 33280

56. Zuo Y, Kim S W, Masui T and Imanaka N 2014 ECS J. Solid State Sci. Technol. 3 R79

57. Lian J, Zhang J, Namavar F, Zhang Y, Lu F, Haider H, Garvin K, Weber W J and Ewing R C 2009 Nanotechnology 20245303 